\title{
Fabrication of Micro Structures by Ultrashort Voltage Pulse Electrical Discharge Machining
}

\author{
Chenxue Wang*, Weiyu He, Yan Xiao \\ Shenzhen Key Laboratory of Advanced Manufacturing Technology for Mould \& Die, Shenzhen University, Shenzhen, China \\ Email: *1432362629@qq.com
}

How to cite this paper: Wang, C.X., He, W.Y. and Xiao, Y. (2018) Fabrication of Micro Structures by Ultrashort Voltage Pulse Electrical Discharge Machining. Journal of Minerals and Materials Characterization and Engineering, 6, 235-243.

https://doi.org/10.4236/jmmce.2018.62017

Received: February 6, 2018

Accepted: March 23, 2018

Published: March 26, 2018

Copyright $\odot 2018$ by authors and Scientific Research Publishing Inc. This work is licensed under the Creative Commons Attribution International License (CC BY 4.0).

http://creativecommons.org/licenses/by/4.0/

\begin{abstract}
The machining of small holes and array holes has been a difficult problem in machining field. Tiny hole is widely used in mechanical field, for instance, fuel injection nozzles, spinneret holes for synthetic fibers and wire drawing dies. This paper investigated the application of EDM (electrical discharge machining) to the fabrication of micro structures. There are obvious limitations in the process of micro-electrical discharge machining, such as electrode wear, unstable discharge condition and low machining efficiency. The effects of EDM parameters were investigated, such as voltage, pulse frequency, and frequency of ultrasonic vibration applied to electrode. Micro holes were machined with Pt electrode made by focused-ion-beam chemical vapor deposition (FIB-CVD) and $\mathrm{Cu}$ electrode made by wire-electrode cutting. The comparison experiments between EDM and ECM (electrochemical machining) indicated that the processing of ECM has serious stray current corrosion and poor machining precision. Moreover, the workpiece vibration was firstly proposed to be utilized in the micro-electrical discharge machining. It can be concluded that maximum machine could be obtained under the amplitude ratio of $76 \%$, which was an appropriate parameter.
\end{abstract}

\section{Keywords}

Micro-EDM (Electrical Discharge Machining), Micro-Holes, Ultrashort Voltage Pulse

\section{Introduction}

Due to the macroscopic cutting forces existing in the traditional machining process, deformation is easily generated when machining minute parts, especially parts of micrometer scale [1]. The accuracy control is more difficult. In addition, the producing surface stress affects the performance of the product [2] [3]. 
But EDM has many advantages that machining force exerted on the electrode and workpiece [4] [5]. It is much lower than traditional machining in machining processes. Furthermore, micro electrical discharge machining becomes an important machining method for micromachining as a result of high performance and precise micro components applied in many fields [6] [7]. In micro-EDM, electrode is the necessary tool for performing micro-ECDM electro-discharge grinding (WEDG) for EDM, in which the tool electrode is a travelling wire so that the effect of electrode wear can be avoided [8] [9] [10]. Egashira et al. used silicon probes which are originally used for scanning probe microscopes (SPM) as electrode for micro-EDM [11]. Takahata et al. utilized LIGA process to fabricate high aspect ratio electrode arrays, hence batch mode micro-EDM could be achieved [12] [13]. The electrode fabricated by FIB-CVD was used for micro-EDM. With the further research and application of the micro-EDM technology, people are more and more realize that the current research on the basic theory of the micro-EDM has become a huge resistance to the further development of the technology [14] [15]. The theoretical basis of EDM is to predict the machining efficiency, the loss of tool electrodes, and machining surface quality [16] [17]. However, owing to the randomness of spark discharge and the lack of research methods, it is difficult to predict the process accurately. Especially for the micro-hole EDM process, discharge energy and discharge gap are very small, the discharge point in time and space highly concentrated, resulting in very unstable and low efficiency process. This paper aims to research the basic rules of the micro-EDM.

\section{Experiments}

\subsection{Experimental Set-Up}

The schematic diagram of micro EDM system was shown in Figure 1. The whole

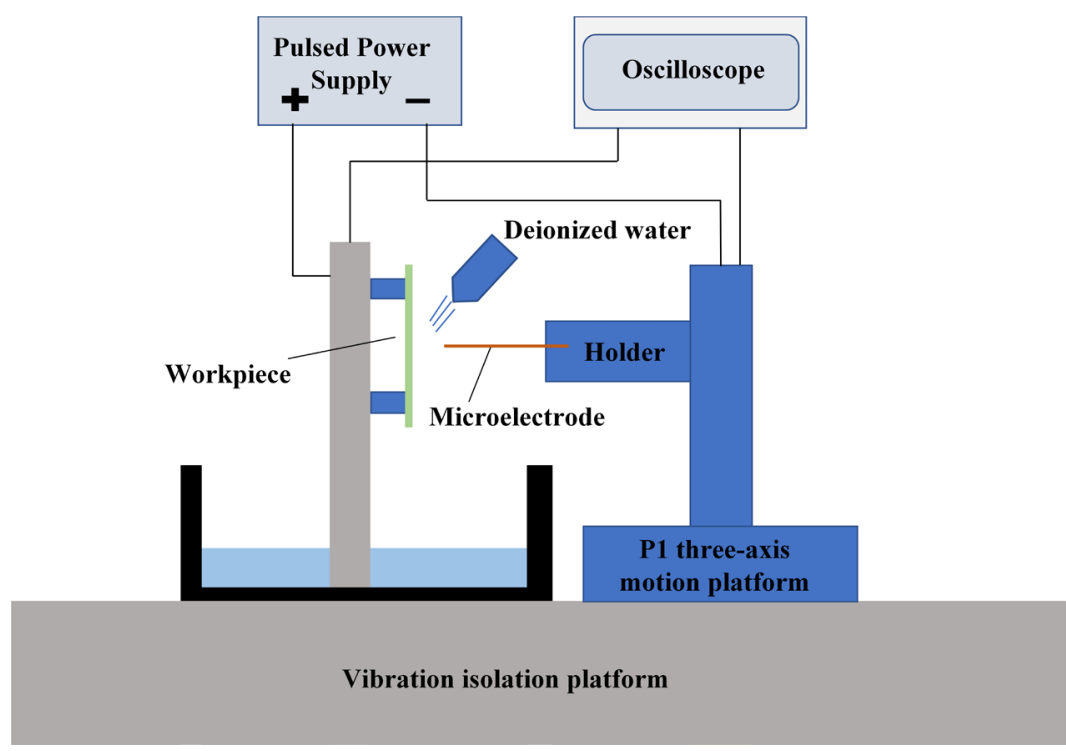

Figure 1. Schematic diagram of micro ECM/EDM system. 
equipment consists of three parts: the home-made pulse generator, P1 motion platform, electrode clamp and liquid injection circulator unit. The home-made pulse generator can provide short voltage pulse for EDM and ECM process. The $\mathrm{P} 1$ motion platform is made of three piezo-driven $\mathrm{x}-\mathrm{y}-\mathrm{z}$ stages with $0.1 \mu \mathrm{m}$ solution. The auxiliary system consists of electrolytic cell, amperemeter and oscilloscope and ultrasound-assisted system.

\subsection{Manufacture of Tool}

The higher corrosion resistance and the smaller the electrode loss, the higher the square accuracy. Therefore, selecting the copper electrode with high corrosion resistance and low price for EDM. FIB-CVD (focused-ion-beam chemical vapor deposition) can produce electrodes with a small diameter; the electrode is prepared with the common material platinum. Two kinds of electrodes were used in the machining process. Firstly, Pt electrode was fabricated by focused-ion-beam chemical vapor deposition. Microelectrode in the material of amorphous Pt was deposited in the tip surface of a needle with a diameter of $10 \mu \mathrm{m}$ and a length of $50 \mu \mathrm{m}$. The square electrode was machined by electrical discharge wire cutting machine and the material of the electrode is brass. The sectional dimension of brass electrode is $80 \mu \mathrm{m} \times 80 \mu \mathrm{m}$. Two types of electrode are shown in Figure 2 .

\section{Results and Discussion}

\subsection{Effects of Open Voltage and Pulse Width on the Machining Precision and Unilateral Discharge Gap}

The influence of the open voltage and pulse width on EDM was investigated. The experiments were carried out on the polished 304 austenite stainless steel with $50 \mu \mathrm{m}$-length Pt electrode. The deionized water was working fluid and side flush was adopted considering the convenient drainage of deep holes. For easy processing, positive machining was used in the EDM. Different open voltage and different pulse widths were applied to the machining. The unilateral discharge

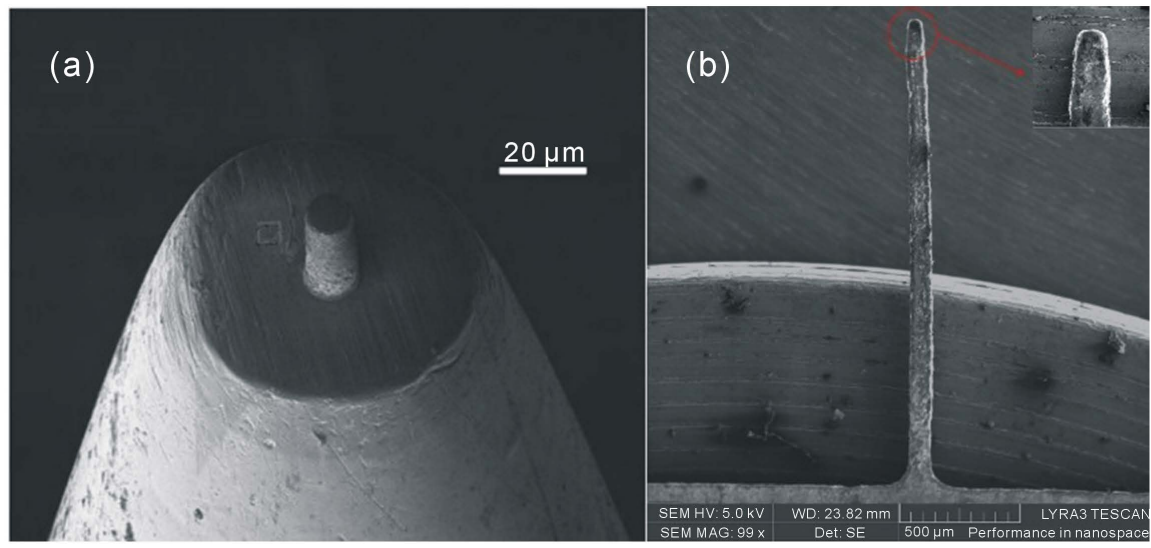

Figure 2. (a) Microelectrode fabricated on the polished tip surface of a needle; (b) The square electrode was machined by electrical discharge wire cutting machine. Sectional dimension size $(80 \times 80 \mu \mathrm{m})$. 
gap was calculated by the equation:

$$
U=(D-d) / 2 .
$$

Open voltage dependencies of hole diameter and unilateral discharge gap are presented in Figure 3.

It is pointed out that the hole diameter increased with the rise of voltage. It is hard to machine an obvious hole under the voltage of $10 \mathrm{~V}$. Different pulse widths (60 ns, $20 \mathrm{~ns}, 800 \mathrm{~ns}$ ) were used in the experiments, and the processing results showed that the hole depth and hole diameter increased in a nonlinear way with the increase of pulse width. To estimate the single pulse energy, a relation between holes diameter and main work parameter is proposed, given by:

$$
W o=\int_{0}^{t i} u(t) i(t) d t .
$$

It can be confirmed that the single discharge crater was decided by the single pulse energy. The larger the discharge voltage, the larger the pulse width and the holes diameter were. Furthermore, the feature of the machined electrode and initial electrode are shown in Figure 4. It is observed that the surface of electrode was covered with a certain thickness, and a quantity of black material adheres to the surface, which further made it rougher and thicker. It can be explained by the formation of a coating layer on the electrode in the processing of EDM,

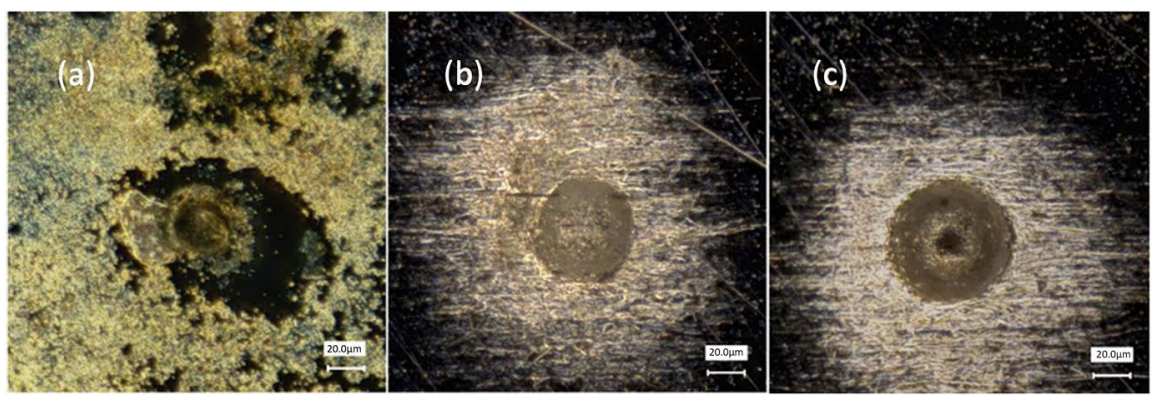

Figure 3. Micro-holes fabricated in the polished 304 austenite by Pt electrode: (a) Open voltage of $10 \mathrm{~V}$; (b) $12.5 \mathrm{~V}$; (c) $15 \mathrm{~V}$.
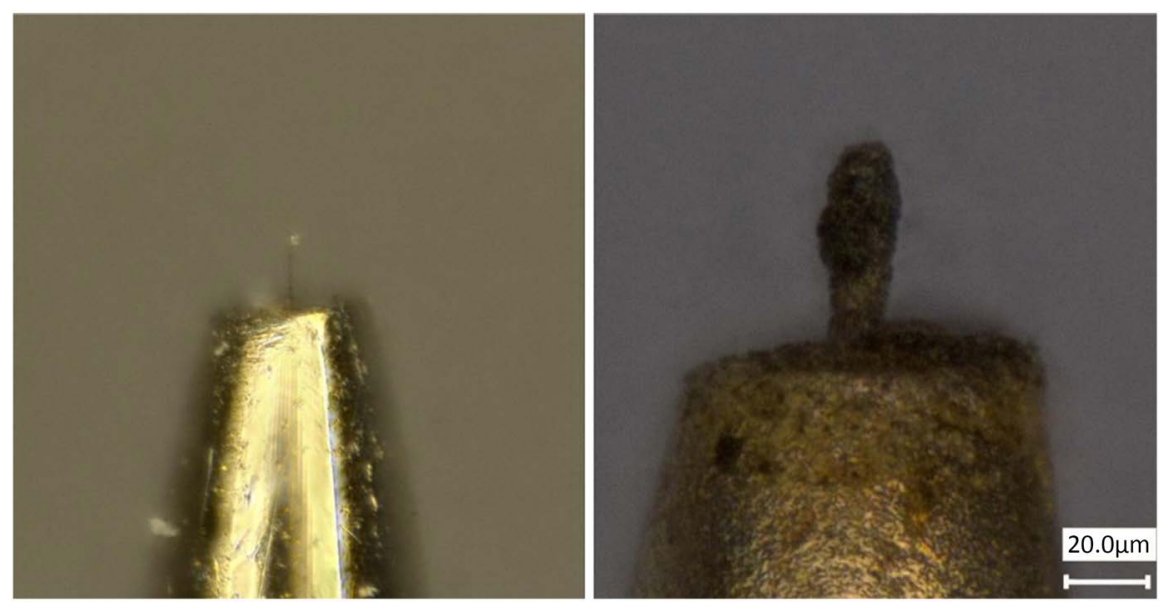

Figure 4. The initial electrode and the electrode morphology after machining. 
which was beneficial for reducing the electrode loss and caused the distortion of the electrode due to the corrosion resistance of the carbon layer.

\subsection{Comparison of Machining Results of EDM with Electrochemical Machining}

For evaluating the machining characteristics between EDM and ECM, comparison experiments were carried out with square electrode. The electrode was fabricated by electrical discharge wire cutting machine into the size of $80 \mu \mathrm{m} \times 80$ $\mu \mathrm{m}$. The workpiece material and machining parameters are shown in Table 1.

In the experiments, square electrode was used to machine a micro hole on 304 stainless sheet with different working fluid. In the results in Figure 5 obtained by our experiments suggest that the diameter of micro hole fabricated by micro-ECM was larger than that processed by micro-EDM. It is illustrated in Figure 6 that the machining zone of ECM was enlarged as the processing was enlarged.

However, the diameter of micro-hole fabricated by EDM would stabilize within a certain range. Compared with ECM, the electrical discharge machining

Table 1. Parameters of machining.

\begin{tabular}{cc}
\hline Fabrication parameters & Value \\
Microelectrode diameter & $80 \times 80 \mu \mathrm{m}$ \\
Workpiece fluid & Deionized Water $2.5 \mathrm{~g}^{2} \mathrm{~L} \mathrm{NaNO}_{3}$ \\
Workpiece & SUS304 $(\mathrm{t}=30 \mu \mathrm{m})$ \\
Open voltage & $10,15,20 \mathrm{~V}$ \\
Pulse width & $60 \mathrm{~ns}$ \\
Working step & $0.5 \mu \mathrm{m}$
\end{tabular}

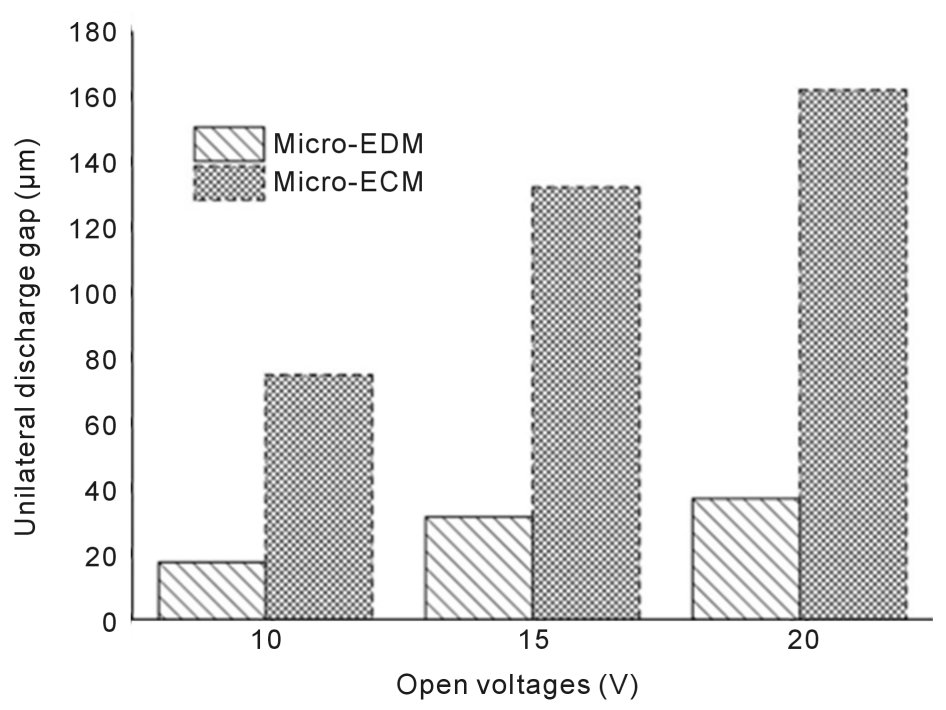

Figure 5. The machining unilateral discharge gap between EDM and ECM in the different open voltages. 


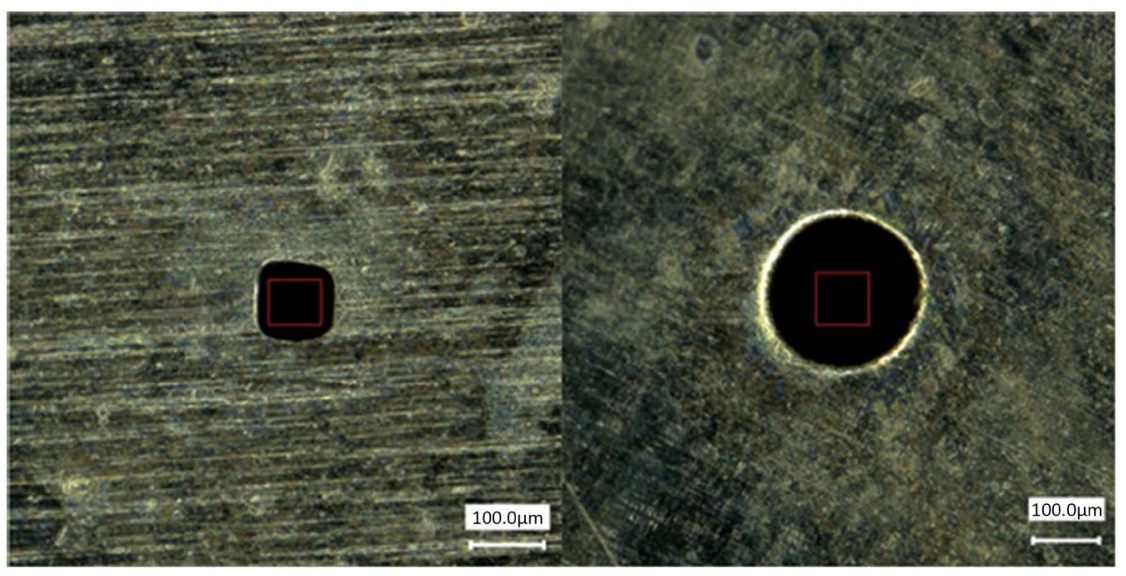

Figure 6. (a) Work piece after micro-EDM with $10 \mathrm{~V}$; (b) Work piece after micro-ECM with $10 \mathrm{~V}$, the red rectangle is the shape of electrode section.

exhibited better performance in machining localization and machining accuracy. It was because the amount of erosion product was greater than the expected value of Faraday's law in ECM, which meant the corrosion of surrounding metals of anode increased as the reaction time increased. Meanwhile, the micro-ECM processing was simulated using COMSOL, which accorded with the results of experiments. As shown in Figure 7, with the processing time increased, the unilateral gap became larger, and the entrance taper of micro hole gets huger according to the simulation result. The unilateral gap was $76 \mu \mathrm{m}$ which was consistent with the machining date. It was clarified that there were some contradictions between machining efficiency and machining precision due to its stray etching.

\subsection{The Influence of Workpiece Vibration on EDM}

Considering debris removal from the hole is a key factor in micro-EDM. The ultrasound-assisted workpiece machining was researched by drilling micro-holes. The workpiece clamp was installed with ultrasonic transducer connected to ultrasonic generator. The experiment setup is shown in Figure 8.

An approach of micro-EDM by ultrasonic vibration assisted workpiece was implemented on the polished 304 austenite stainless with a theoretical machining depth of $200 \mu \mathrm{m}$. The ultrasonic vibration of different amplitude ration was applied to the workpiece, as shown in Figure 9. It was demonstrated that machining hole depth increased in a certain amplitude and machining time decreased with an amplitude ratio of $0 \%-76 \%$. Most obviously, the optimum vibration ratio of machine was $76 \%$. It indicated that ultrasonic vibration assisted to workpiece would prompt the processing of micro-EDM as well as greatly shorten the machining time. It was speculated that the ultrasonic vibration could enhance the fluidity of the working fluid, avoiding the accumulation of the erosion product, and the ultrasonic vibration produced the cavitation which removed the debris due to the sudden pressure drop. Contributing to small machining zone, the electrode was likely to reach the short circuit current. 


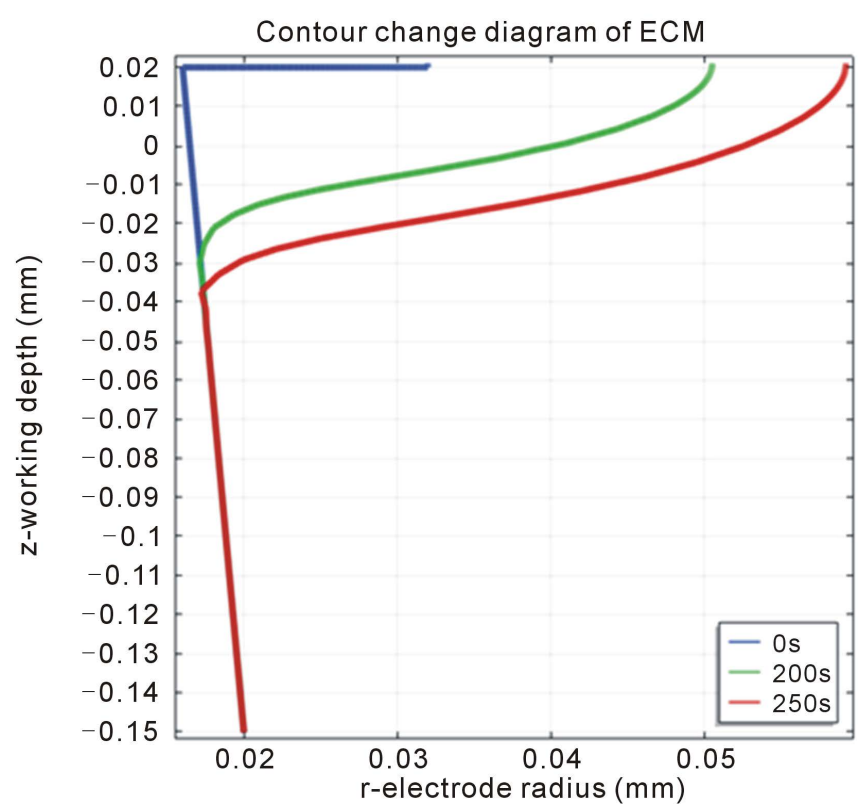

Figure 7. The contour change diagram of ECM, three lines are the contour plot of the corresponding processing time.

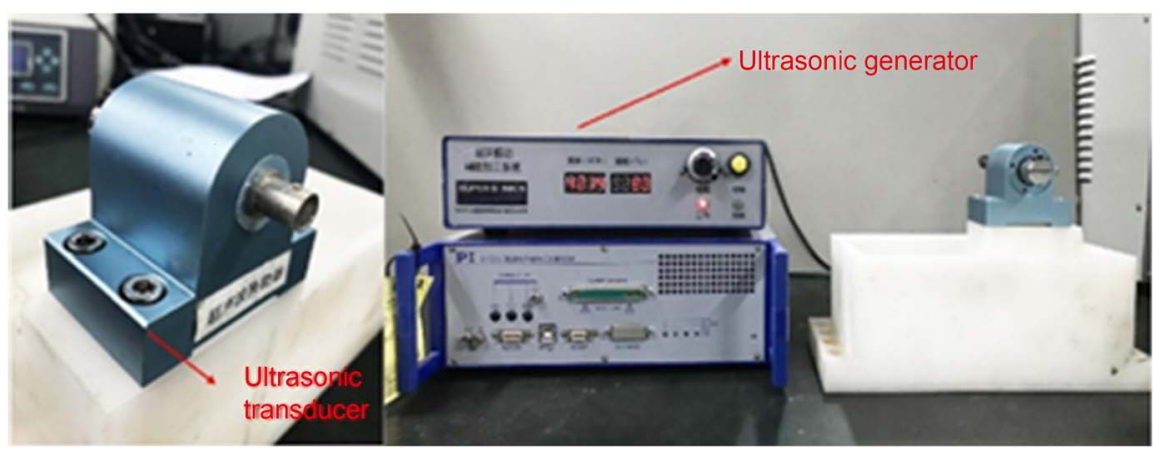

Figure 8. Ultrasonic vibration assisted device.

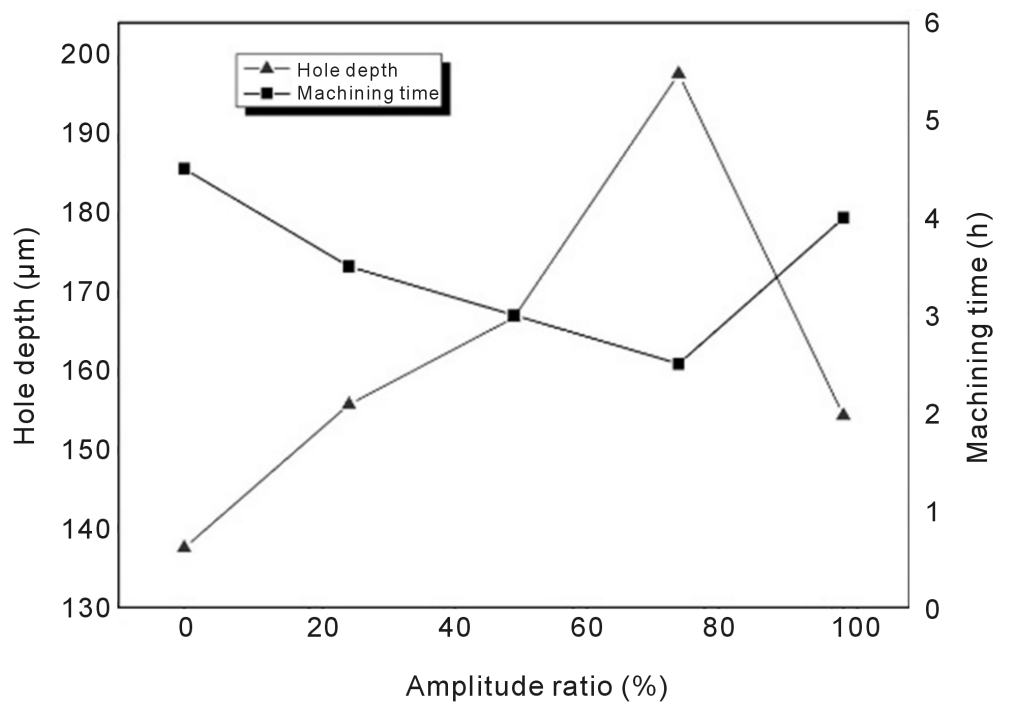

Figure 9. Effects of amplitude ration on hole depth and machining time. 
Additionally, tiny vibration of workpiece would alter the phenomenon that electrode was repeatedly moved or backed as inertial motion and improved the machining efficiency of micro-hole.

\section{Conclusion}

In this research, the micro hole with a submicro precision was fabricated using micro-EDM, applying the FIB-CVD to the EDM/ECM. The feasibility of using ultra-short electrode deposited by FIB to manufacture micro mould by EDM was proved. In the experiment, square electrode was used to machine SUS304. The results showed that micro-EDM had better machining precision under shorter voltage pulse and confining etching location of micro-ECM revealed by simulation results. It was found that the workpiece vibration in the direction of processing effectively contributed to obtain better matching effect of micro-EDM. The appropriate amplitude ratio was $76 \%$.

\section{Acknowledgements}

This work was supported by the Shenzhen Key Laboratory of Advanced Manufacturing Technology for Mould \& Die. The authors appreciated Prof. Guo's help.

\section{References}

[1] Abbas, N.M., Solomon, D.G. and Bahari, M.F. (2007) A Review on Current Research Trends in Electrical Discharge Machining (EDM). International Journal of Machine Tools and Manufacture, 47, 1214-1228.

[2] Abbas, N.M. and Kunieda, M. (2016) Micro-EDM with Controlled Pulse Train Method Using Small Feeding Capacitance. Procedia CIRP, 42, 737-742. https://doi.org/10.1016/j.procir.2016.02.311

[3] Ablyaz, T.R., Simonov, M.Y., Schlykov, E.S. and Muratov, K.R. (2016) Surface Analysis of Bimetal After EDM Machining Using Electrodes with Different Physical and Mechanical Properties. Research Journal of Pharmaceutical, Biological and Chemical, 7, 974-981.

[4] Wang, Y.K., Chen, X., Wang, Z.L., Li, H.C. and Liu, H.Z. (2016) Fabrication of Micro-Rotating Structure by Micro Reciprocated Wire-EDM. Journal of Micromechanics and Microengineering, 26, 11.

[5] Waurzyniak, P. (2016) EDM Advances Spark Manufacturing Productivity. Manufacturing Engineering, 157, 140-144.

[6] Adamovic, N. and Vujanic, A. (2007) Development of UV-LIGA Integrated Vibrometer Using $3 \times 3$ Directional Coupler. Microelectronic Engineering, 84, 1325-1328. https://doi.org/10.1016/j.mee.2007.01.180

[7] Aich, U. and Banerjee, S. (2017) Characterizing Topography of EDM Generated Surface by Time Series and Autocorrelation Function. Tribology International, 111, 73-90. https://doi.org/10.1016/j.triboint.2017.02.016

[8] Parthiban, M., Krishnaraj, V., Sindhumathi, R. and Valentincic, J. (2017) Investigation on Manufacturing of Microtools Made of Tungsten Carbide Using Wire Electric Discharge Grinding (WEDG). Journal of the Brazilian Society of Mechanical Sciences, 39, 3571-3580. https://doi.org/10.1007/s40430-017-0780-2

[9] Srivastava, A., So, J.K., Sattorov, M.A., Kwon, O.J., Park, G.S., Baik, C.W., Kim, J.H. 
and Chang, S.S. (2009) $100 \mathrm{GHz}$ LIGA-Fabricated Coupled-Cavity Device. 2009 IEEE International Vacuum Electronics Conference, Rome, 28-30 April 2009, 102-103. https://doi.org/10.1109/IVELEC.2009.5193373

[10] Torres, A., Puertas, I. and Luis, C.J. (2016) EDM Machinability and Surface Roughness Analysis of INCONEL 600 Using Graphite Electrodes. International Journal of Advanced Manufacturing Technology, 84, 2671-2688.

https://doi.org/10.1007/s00170-015-7880-x

[11] Takezawa, H., Muramatsu, T., Mohri, N. and Fukuzawa, Y. (2010) Characteristics of Electrical Discharge Machining for Magnetic Material. Proceedings of the 16th International Symposium on Electromachining, 2010, 169-173.

[12] Viskic, J., Schauperl, Z., Catic, A., Balog, M., Krizik, P., Grzeta, B., Popovic, J., Ortolan, S.M. and Mehulic, K. (2014) Effects of Wire EDM on the Microstructure of P/M Titanium Samples. Acta Stomatologica Croatica, 48, 285-291. https://doi.org/10.15644/asc48/4/6

[13] Bonny, K., De Baets, P., Van Wittenberghe, J., Delgado, Y.P., Vleugels, J., Van der Biest, O. and Lauwers, B. (2010) Influence of Electrical Discharge Machining on Sliding Friction and Wear of WC-Ni Cemented Carbide. Tribology International, 43, 2333-2344. https://doi.org/10.1016/j.triboint.2010.08.008

[14] Zhang, Y., Xu, Z.Y., Zhu, D., Qu, N.S. and Zhu, Y. (2016) Drilling of Film Cooling Holes by a EDM/ECM in Situ Combined Process Using Internal and Side Flushing of Tubular Electrode. International Journal of Advanced Manufacturing Technology, 83, 505-517. https://doi.org/10.1007/s00170-015-7575-3

[15] Zivanovic, S. and Puzovic, R. (2016) Wire Edm Machining Simulations Based on Step-Nc Program. Tehnicki Vjesnik, 23, 1831-1838.

[16] Ay, M., Caydas, U. and Hascalik, A. (2013) Optimization of Micro-EDM Drilling of Inconel 718 Superalloy. International Journal of Advanced Manufacturing Technology, 66, 1015-1023. https://doi.org/10.1007/s00170-012-4385-8

[17] Baik, C.W., So, J.K., Sattorov, M.A., Srivastava, A., Jang, K.H., Won, J.H., Son, Y.M., Kim, S.I., Kim, J.M., Kim, J.H., Chang, S.S. and Park, G.S. (2008) Comparative Analysis on DRIE and LIGA Fabrications for Millimeter-Wave Backward-Wave Oscillators. 2008 33rd International Conference on Infrared, Millimeter and Terahertz Waves, Pasadena, 15-19 September 2008, 1-2.

https://doi.org/10.1109/ICIMW.2008.4665443 